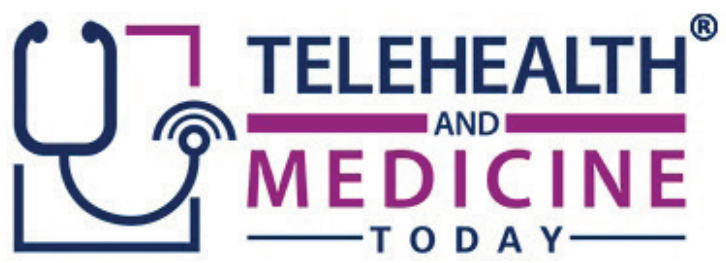

\title{
Uses of Telehealth to Support Identification and Treatment of Health Disorders in the Criminal Justice System
}

\section{Saira Naim Haque}

Affiliations: RTI International, Research Triangle Park, NC, USA

Corresponding Author: Saira Naim Haque, Email: shaque@rti.org

Keywords: Criminal Justice, mHealth, Remote Monitoring, Telehealth, Telemedicine

Section: Opinions, Perspectives and Commentary on a current trend or issue impacting the sector

Telehealth, the interactive, electronic exchange of information for diagnosis, treatment, support, or care management, is a critical component of many systems of care. ${ }^{1}$ The variety of telehealth uses, technologies, and approaches, when implemented successfully, can improve access to care and overcome typical geographic and workforce barriers. ${ }^{1}$ The opioid epidemic and recent social distancing requirements due to coronavirus disease (COVID-19) have prompted public safety, behavioral health, and other community partners to explore how telehealth can be used for identification and treatment of disorders in the criminal justice system.

Telehealth offers an innovative strategy for intervention and treatment within the criminal justice system, which is greatly needed given the prevalence of justice-involved populations affected by opioid-use disorder. For one, it is costly to provide treatment and care to people who are incarcerated, and telehealth can help reduce that cost. ${ }^{2}$ Using telehealth to connect these people to providers can also help avoid resource-heavy and potentially dangerous transfers to care settings. In addition, a telehealth strategy can minimize the burden associated with recruiting and retaining healthcare providers on site, particularly behavioral health providers, who are often in short supply.

Offering options virtually is one way to ameliorate organizational challenges. Services that can be provided via telehealth include inpatient and outpatient medical services, behavioral health, physical and occupational therapy, disaster management, health education, ${ }^{1}$ and coordination of care support for inmates, providers, and officials. Telehealth can also be used to facilitate release of inmates by connecting people who are in prison or jail with community-based services before release. 
$\mathrm{T}$ This narrative describes the types of telehealth and how each can be used in the criminal justice system to support identification and management of health disorders for inmates. The recent social distancing requirements due to COVID-19 have prompted public safety, behavioral health, and other community partners to explore how telehealth can be used to support their goals.

\section{TYPES OF TELEHEALTH SERVICES USED IN CRIMINAL JUSTICE}

Different types of telehealth include technologies that can be delivered in real time (synchronous) such as live video - or technologies delivered with some delay (asynchronous) — such as store and forward, remote patient monitoring (RPM), and mobile health (mHealth). ${ }^{3}$

\section{Live Video}

"Live, two-way interaction between a person (patient, caregiver, or provider) and a provider using audiovisual telecommunications technology." (p. 5) $)^{3}$

Real-time (synchronous) interaction using video is the most common use of telehealth. Providers, criminal justice officials, and social workers can use live video for early intervention, case review coordination, and education. Emergency medical services personnel use telehealth to provide prehospital consultations for a variety of purposes. ${ }^{4}$ One example is using telehealth technology when responding to a call about someone in a potential overdose situation to determine the most appropriate next steps in real time, whether those steps are related to criminal justice or health care. People who are incarcerated can also receive direct primary and specialty care through live video. Using live video to connect people with community providers can help them develop a relationship that can be retained even after release. This is of particular importance for ongoing care for long-term conditions such as diabetes, which require continuity of management.

\section{Store and Forward}

"Transmission of videos and digital images such as $x$-rays and photos through a secure electronic communications system. As compared to a 'realtime' visit, this service provides access to data after it has been collected." (p. 5) ${ }^{3}$

Store and forward technology is not a real-time (synchronous) interaction but is asynchronous. This means that providers review data that have been provided to them. For example, if someone has been receiving care in a correctional facility, the community provider who will be taking care of the person upon release may review information collected through the course of care in the correctional facility and use that to inform decision-making. Other examples of store and forward technology include chart review to support e-consultations for care planning for chronic conditions such as asthma, cardiovascular disease, or diabetes.

\section{Remote Patient Monitoring}

"Personal health and medical data collection from an individual in one location, which is transmitted to a provider in a different location." (p. 5)

RPM is typically asynchronous and uses technology such as blood glucose monitors to transmit information about patients to providers for review. Providers can review trends and modify patient care plans based on those data without needing to travel to the facility or without transferring an inmate to a community provider for care. This can help improve glycemic index control among people with diabetes and help reduce the necessity for in-person visits. For behavioral health, RPM could be used to integrate regular data collection about behavioral and emotional triggers into 
ongoing care planning and ensuring that people seek help as needed upon release.

\section{Mobile Health}

"Smartphone apps designed to foster health and well-being." (p. 5) ${ }^{3}$

mHealth is also typically asynchronous. Its primary purpose is to engage patients and caregivers. Apps vary in sophistication, from text message reminders aimed at behavior change to sophisticated sensors that share patient-generated health information with providers. Apps could be used to encourage people's compliance with disease management programs upon release from prison or jail and to support peer counseling programs. mHealth can also be used to reinforce medication use and behavior change.

\section{CONSIDERATIONS WHEN IMPLEMENTING TELEHEALTH IN CRIMINAL JUSTICE SETTINGS}

Five key domains to consider for telehealth in the criminal justice system include selecting services, identifying related policies and procedures, training staff, preparing patients, and analyzing costs and benefits.

\section{Selecting services}

Selecting the type of telehealth services is based on factors such as needs of the population, availability of providers, and feasibility of providing the service. Another way to identify services to provide is to examine overall population health areas that need improvement that could be refined through telehealth. ${ }^{5}$

\section{Identifying and modifying organizational policies and procedures}

After service selection, criminal justice officials must review how telehealth will affect their facilities. Items to review include roles and responsibilities, scheduling and workflow, assessment approaches, technical infrastructure, and physical space and security. It might be difficult to find an appropriately private and secure place with connectivity in a facility, so this must be addressed as part of implementation planning. In addition, coordination and information exchange between the originating site (i.e. where the patient is located) and the distant site (i.e. where the provider is located) must be considered. Legal and regulatory considerations must be monitored as well, such as changing rules around electronic consents, security, and provider types eligible to provide services. ${ }^{6,7}$ A variety of regulations must be considered around offering virtual services and prescribing. These include regulations around payment options upon release, types of providers who can offer telehealth services, and locations of patients and providers.

\section{Training staff}

Staff roles and responsibilities will change with telehealth implementation, and these changes vary with the security of the facility. Thus, it is important that leaders take an active, hands-on role in supporting telehealth implementation to infuse support and engage staff throughout the organization. ${ }^{6-8}$ As with any change, considering staff members' perspectives before, during, and after telehealth implementation can promote successful implementation. Identifying champions and promoting education and awareness are two considerations that will improve the chances of successful implementation.

\section{Preparing patients}

Many people may be intimidated by technology or may not be used to interacting with providers using technology. It is important to understand the population's experience with technology and access to devices such as tablets (in facilities and upon reentry) to understand whether they will be amenable to telehealth. ${ }^{7}$ Those with high health 
literacy are more likely to embrace telehealth ${ }^{9,10}$ than those with lower health literacy. ${ }^{11}$ In addition, it is important to prepare people and identify needs for telehealth post-release such as the need for a private space, need for a device, and internet or cellular connectivity. If people see the benefits of telehealth and how it can help them, they will be more motivated to use it and see better outcomes even when they are no longer incarcerated. ${ }^{12}$

\section{Analyzing costs and benefits}

Costs and benefits of telehealth will vary by the type of service selected and the institution. ${ }^{13-16}$ Telehealth can affect physical infrastructure, technical infrastructure, workflow, and cost. ${ }^{9,17}$ Telehealth programs have a variety of funding sources such as states, federal programs, foundations, and payers. ${ }^{18}$ Regardless of the funding source, identifying telehealth's costs and benefits (e.g. improved outcomes, reduced costs, avoided costs) is critical.

\section{CONCLUSIONS}

Many facilities are already using telehealth to help improve care and reduce costs throughout the criminal justice system. The COVID-19 pandemic has highlighted the utility of telehealth in providing vital services to people during incarceration and reentry. Telehealth can be used in several ways, such as supporting peer counseling, increasing access to specialty services, and supporting transitions upon reentry. Telehealth can improve access to care, enhance care coordination, and reduce costs of providing care to people who are incarcerated. In addition, telehealth can be used to prepare people for release from prison or jail and improve coordination of care during community reentry. To achieve the promise of telehealth, grantees should consider their readiness to participate in using telehealth. Selecting services, identifying and implementing changes to policies and procedures, training staff, preparing patients, and analyzing costs and benefits must be addressed before telehealth implementation or expansion.

Funding Statement: This was funded by internal organizational funding. The funders had no role in study design, data collection and analysis, decision to publish, or preparation of the manuscript.

Conflicts of Interest:The author has no financial conflict of interest to report.

Contributor:This was a sole-authored work.

\section{REFERENCES}

1. Center for Connected Health Policy (CCHP). Home page. n.d [cited 2020 Nov 23]. Available from: https://www.cchpca.org

2. Chari KA, Simon AE, DeFrances CJ. National Survey of Prison Health Care: Selected findings. National Health Statistics Reports; No. 96. Hyattsville, MD: National Center for Health Statistics; 2016 [cited 2020 Nov 23]. Available from: https://www.bjs. gov/index.cfm?ty $=$ pbdetail\&iid $=5705$

3. Office of Health Policy, Office of the Assistant Secretary for Planning and Evaluation (ASPE). E-health and telemedicine. Report to congress. Washington, DC: U.S. Department of Health and Human Services; 2016 [cited 2020 Nov 23]. Available from: https:// aspe.hhs.gov/system/files/pdf/206751/ TelemedicineE-HealthReport.pdf

4. Champagne-Langabeer T, Langabeer JR, et al. Telehealth impact on primary care related ambulance transports. Prehosp Emerg Care. 2019;23(5):712-7. https://doi. org/10.1080/10903127.2019.1568650

5. Arkwright B. Telehealth readiness factors: What are they and why are they essential? Blog post. 2016 [cited 2020 Nov 23]. Available from: https://www. linkedin.com/pulse/telehealth-readinessfactors-what-why-essential-bryan-tarkwright?trk=prof-post 
6. Ross J, Stevenson F, Lau R, et al. Factors that influence the implementation of e-health: A systematic review of systematic reviews (an update). Implement Sci. 2016;11(1):146. https://doi.org/10.1186/ s13012-016-0510-7

7. Georgsson M, Staggers N. Patients' perceptions and experiences of a mHealth diabetes self-management system. Comput Inform Nurs. 2017;35(3):122-30. https:// doi.org/10.1097/cin.0000000000000296

8. California Telemedicine and eHealth Center (CTEC). Assessing organizational readiness: Is your organization ready for telemedicine? Discovery series. Sacramento, CA: CTEC; 2009 [cited 2020 Nov 23]. Available from: http://www.caltrc.org/wp-content/ uploads/2013/10/08-1129-final_ctec_ discovery_series.pdf

9. Kruse CS, Karem P, Shifflett K, et al. Evaluating barriers to adopting telemedicine worldwide: A systematic review. J Telemed Telecare. 2018;24(1):4-12. https://doi. org/10.1177/1357633x16674087

10. Kruse CS, Krowski N, Rodriguez B, et al. Telehealth and patient satisfaction: A systematic review and narrative analysis. BMJ Open. 2017;7(8):e016242. https://doi. org/10.1136/bmjopen-2017-016242

11. Paige SR, Krieger JL, Stellefson M, et al. eHealth literacy in chronic disease patients: An item response theory analysis of the eHealth literacy scale (eHEALS). Patient Educ Couns. 2017;100(2):320-6. https://doi.org/10.1016/j.pec.2016.09.008

12. Bullock DR, Vehe RK, Zhang L, et al. Telemedicine and other care models in pediatric rheumatology: An exploratory study of parents' perceptions of barriers to care and care preferences. Pediatr Rheumatol Online J. 2017;15(1):55. https:// doi.org/10.1186/s12969-017-0184-y

13. Ferreira A. Steps to telehealth success: Organizational readiness. Amwell Blog. 2016 [cited 2020 Nov 23]. Available from: https://business.amwell.com/stepsto-telehealth-success-organizationalreadiness/

14. Gagnon MP, Duplantie J, Fortin JP, et al. Implementing telehealth to support medical practice in rural/remote regions: What are the conditions for success? Implement Sci. 2006;1:18. https://doi. org/10.1186/1748-5908-1-18

15. Gagnon MP, Ngangue P, Payne-Gagnon J, et al. m-Health adoption by healthcare professionals: A systematic review. $J$ Am Med Inform Assoc. 2016;23(1):212-20. https://doi.org/10.1093/jamia/ocv052

16. Nacci PL, Turner CA, Waldron RJ, et al. Implementing telemedicine in correctional facilities. Joint program steering group report. Washington, DC: National Institute of justice; 2002 [cited 2020 Nov 23]. Available from: https://www.ncjrs.gov/ pdffiles1/nij/190310.pdf

17. Effertz G, Alverson DC, Dion D, et al. Sustaining and expanding telehealth: A survey of business models from selected prominent U.S. telehealth centers. Telemed $J$ E Health. 2017;23(2):137-42. https://doi. org/10.1089/tmj.2016.0023

18. Adler-Milstein J, Kvedar J, Bates DW. Telehealth among US hospitals: Several factors, including state reimbursement and licensure policies, influence adoption. Health Aff (Millwood). 2014;33(2):207-15. https://doi.org/10.1377/hlthaff.2013.1054

Copyright Ownership: This is an open access article distributed in accordance with the Creative Commons Attribution Non Commercial (CC BY-NC 4.0) license, which permits others to distribute, adapt, enhance this work non-commercially, and license their derivative works on different terms, provided the original work is properly cited and the use is noncommercial. See: http://creativecommons. org/licenses/by-nc/4.0. 